\title{
Can we predict patient outcome before extracorporeal membrane oxygenation for refractory cardiac arrest?
}

Fu-Yuan Siao ${ }^{1,2,3 \dagger}$, Chun-Wen Chiu ${ }^{1 \dagger}$, Chun-Chieh Chiu', Yu-Jun Chang ${ }^{4}$, Ying-Chen Chen ${ }^{5}$, Yao-Li Chen ${ }^{5}$, Yung-Kun Hsieh ${ }^{5}$, Chu-Chung Chou ${ }^{1}$ and Hsu-Hen Yen ${ }^{6,7^{*}}$ (D)

\begin{abstract}
Background: Refractory cardiac arrest resistant to conventional cardiopulmonary resuscitation (C-CPR) has a poor outcome. Although previous reports showed that extracorporeal cardiopulmonary resuscitation (E-CPR) can improve the clinical outcome, there are no clinically applicable predictors of patient outcome that can be used prior to the implementation of E-CPR. We aimed to evaluate the use of clinical factors in patients with refractory cardiac arrest undergoing E-CPR to predict patient outcome in our institution.
\end{abstract}

Methods: This is a single-center retrospective study. We report 112 patients presenting with refractory cardiac arrest resistant to C-CPR between January 2012 and November 2017. All patients received E-CPR for continued life support when a cardiogenic etiology was presumed. Clinical factors associated with patient outcome were analyzed. Significant pre-ECMO clinical factors were extracted to build a patient outcome risk prediction model.

Results: The overall survival rate at discharge was 40.2 , and $30.4 \%$ of patients were discharged with good neurologic function. The six-month survival rate after hospital discharge was 36.6, and $25.9 \%$ of patients had good neurologic function 6 months after discharge. We stratified the patients into low-risk $(n=38)$, medium-risk $(n=47)$, and high-risk groups $(n=27)$ according to the TLR score (low-flow Time, cardiac arrest Location, and initial cardiac arrest Rhythm) that we derived from pre-ECMO clinical parameters. Compared with the medium-risk and high-risk groups, the low-risk group had better survival at discharge $(65.8 \%$ vs. $42.6 \%$ vs. $0 \%, p<0.0001)$ and at 6 months ( $60.5 \%$ vs. $38.3 \%$ vs. $0 \%, p=0.0001)$. The low-risk group also had a better neurologic outcome at discharge $(50 \%$ vs. $31.9 \%$ vs. $0 \%, p=0.0001)$ and 6 months after discharge $(44.7 \%$ vs. $25.5 \%$ vs. $0 \%, p=0.0003)$ than the medium-risk and high-risk groups.

Conclusions: Patients with refractory cardiac arrest receiving E-CPR can be stratified by pre-ECMO clinical factors to predict the clinical outcome. Larger-scale studies are required to validate our observations.

Keywords: Refractory cardiac arrest, Out-of-hospital cardiac arrest, In-hospital cardiac arrest, Emergency department cardiac arrest, Extracorporeal cardiopulmonary resuscitation, Extracorporeal membrane oxygenation

\footnotetext{
* Correspondence: 91646@cch.org.tw

${ }^{\dagger}$ Fu-Yuan Siao and Chun-Wen Chiu contributed equally to this work.

${ }^{6}$ Department of Internal Medicine, Changhua Christian Hospital, Changhua,

Taiwan

${ }^{7}$ College of Medicine, Chung-Shan Medical University, Taichung, Taiwan

Full list of author information is available at the end of the article
}

C C The Author(s). 2020 Open Access This article is licensed under a Creative Commons Attribution 4.0 International License, which permits use, sharing, adaptation, distribution and reproduction in any medium or format, as long as you give appropriate credit to the original author(s) and the source, provide a link to the Creative Commons licence, and indicate if changes were made. The images or other third party material in this article are included in the article's Creative Commons licence, unless indicated otherwise in a credit line to the material. If material is not included in the article's Creative Commons licence and your intended use is not permitted by statutory regulation or exceeds the permitted use, you will need to obtain permission directly from the copyright holder. To view a copy of this licence, visit http://creativecommons.org/licenses/by/4.0/ The Creative Commons Public Domain Dedication waiver (http://creativecommons.org/publicdomain/zero/1.0/) applies to the data made available in this article, unless otherwise stated in a credit line to the data. 


\section{Background}

Extracorporeal cardiopulmonary resuscitation (E-CPR) is being increasingly used as an effective supportive tool for prolonged cardiac arrest refractory to conventional cardiopulmonary resuscitation (C-CPR) [1-3]. E-CPR implementation is a complex procedure that requires extensive teamwork for successful cardiopulmonary life support $[4,5]$. The procedure can have major complications, such as massive bleeding and brain injury [6, 7], and it has a high financial burden $[4,8]$. Despite increased E-CPR use for prolonged cardiac arrest, the survival rate varies from $8.8 \%$ [9] to 54\% [10], depending on candidate selection, and the overall survival to discharge is $29 \%$ [11].

Recent guidelines from the American Heart Association recommend E-CPR use as a class IIb recommendation to improve survival in patients with potentially reversible refractoriness to C-CPR [12]. Although E-CPR may help bridge patients to diagnosis or therapy, it may also bridge patients to nowhere, raising ethical concerns [13]. Because E-CPR is usually performed in the emergency setting when the patient is unconscious, it is difficult to conduct large-scale studies to compare E-CPR and C-CPR results in the real world [14]. Data regarding appropriate patient selection criteria for E-CPR from randomized comparative trials are lacking [15]. However, observational clinical studies aimed at identifying those who may least benefit from such advanced techniques are needed to prevent futile extracorporeal membrane oxygenation (ECMO) use [16, 17]. For example, the Survival After Veno-arterial ECMO (SAVE) score was developed to predict patient survival following cardiogenic shock using clinical parameters [18, 19], and the ENCOURAGE mortality risk score from a French study group was proposed to predict mortality in ECMO-treated patients with acute myocardial infarction [20]. Laboratory data and etiology of cardiac arrest are often unknown prior to E-CPR use. Using such prognostic scores is complex and requires clinical information that is typically only available after ECMO use. Prognostic factors, such as low-flow time and cardiac rhythm, were found to be related to survival and neurological outcome in patients with in-hospital cardiac arrest (IHCA) or out-of-hospital cardiac arrest (OHCA) who received E-CPR [21-23]. Such prognostic factors have not been combined to predict survival in patients with refractory cardiac arrest receiving E-CPR. In our previous studies, E-CPR was shown to improve patient survival and neurological outcome [3]. In our experience, traditionally poor prognostic factors, such as low-flow time as long as $250 \mathrm{~min}$ [1] or nonshockable cardiac rhythm [24], can be appropriately managed with E-CPR to achieve good neurological outcome. In the present study, we aimed to review the clinical outcomes of patients in our institution with refractory cardiac arrest receiving E-CPR and identify potentially useful clinical parameters before ECMO therapy initiation to predict patient outcome in this challenging condition.

\section{Methods \\ Patients}

Medical charts between January 2012 and November 2017 in the hospital were retrospectively reviewed. The hospital was the only medical center equipped to perform 24/7 E-CPR service in Changhua County, with an area of $1074 \mathrm{~km}^{2}$ and a population of 1.2 million located in central Taiwan. The Institutional Review Board of Changhua Christian Hospital approved the study (IRB No. 141103). We enrolled patients who fulfilled the following criteria for the E-CPR program: age 18-75 years; cardiac arrest presumed to be of cardiac origin; C-CPR initiated for cardiac arrest within 5 min (no-flow time $\leq$ $5 \mathrm{~min}$ ); and refractory cardiac arrest defined as failure to achieve return of spontaneous circulation (ROSC) after at least $10 \mathrm{~min}$ of $\mathrm{C}-\mathrm{CPR}$.

Patients were excluded if the time from cardiac arrest onset to C-CPR activation was prolonged or unknown. They were also excluded if they had severe head trauma, acute active bleeding, severe sepsis, terminal cancer, or any history of severe neurological deficits (including dementia, ischemic stroke, intracranial hemorrhage, and bedridden state). In total, 112 patients with refractory cardiac arrest were identified and enrolled in this study (Fig. 1). OHCA was defined as cardiac arrest occurring outside the hospital, and IHCA was defined as cardiac arrest occurring in the hospital during hospital admission. Emergency department cardiac arrest (EDCA) was defined as cardiac arrest occurring in the emergency department. The low-flow time represents the period from initiation of any CPR (either bystander CPR or professional CPR) to initiation of femoral cannulation [3].

\section{Assessment of resuscitation process and clinical outcome}

The number of cardiac arrests, etiology of cardiac arrest, cardiac arrest rhythm, and time from CPR to ECMO were retrospectively reviewed. Sustained ROSC was defined as > $20 \mathrm{~min}$ of spontaneous circulation without cardiac arrest recurrence. Neurological outcome was evaluated using the Glasgow-Pittsburgh cerebral performance category (CPC) scale. Good neurological outcome was defined as a CPC score of 1 or 2 , poor neurological function as a CPC score of 3 or 4 , and brain death as a CPC score of 5 . Patients were evaluated for survival and good neurological function at discharge and 6 months after discharge. Information on the patients who survived E-CPR until hospital discharge was collected from medical records and telephone interviews. 


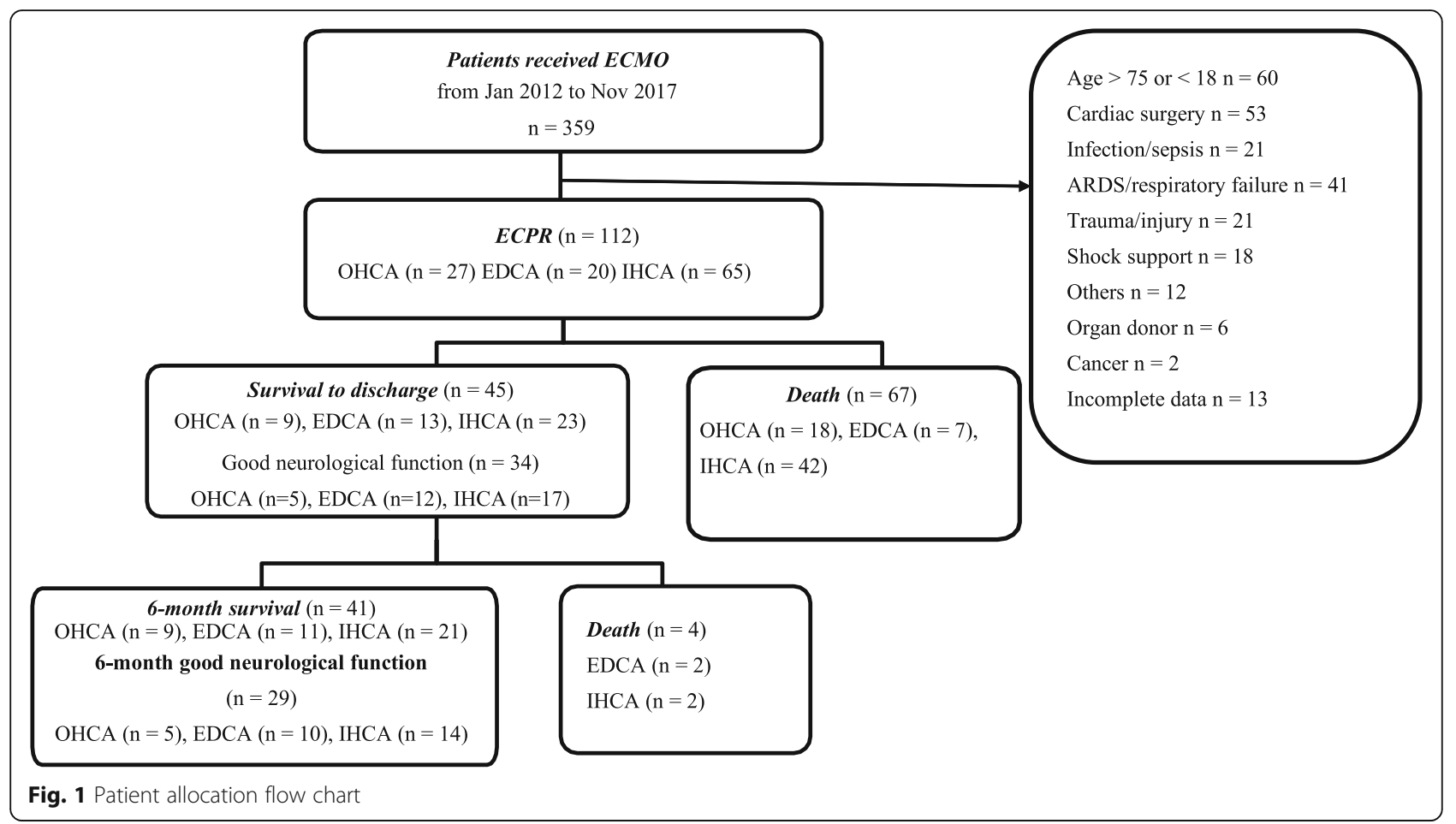

\section{ECMO system and intervention}

In our hospital, E-CPR was initiated as an option for prolonged CPR. The attending physician and our ECMO team will discuss the patient's situation and make the judgment in terms of above-mentioned inclusion criteria. The ECMO system included a centrifugal blood pump, oxygenator, patient outflow cannula, and patient inflow cannula. The pump flow was controlled to maintain a minimum flow of $2.0 \mathrm{~L} / \mathrm{min}$. The activated clotting time was maintained at 180-220 s with heparin. We implemented E-CPR via femoral cannulation in the emergency department, regular medical ward, intensive care unit, or cardiac catheterization laboratory. Patients who achieved sustained ROSC after ECPR were transferred to subsequent intervention for diagnosis and treatment. The patient was declared dead if ROSC was not achieved after 90 min of E-CPR. Emergency coronary angiography was performed for patients with suspected acute coronary syndrome. Targeted temperature management was considered when the patient remained comatose after ROSC and was determined by the attending physician of the intensive care unit.

\section{Statistical analyses}

Demographic data and other clinical data of continuous variables are presented as median and interquartile range (IQR, 25th-75th percentile), whereas categorical variables are presented as number and percentage. Independent variables were first analyzed by univariate methods. The Mann-Whitney $U$ test was used to compare median values of continuous variables between the groups, whereas the chi-square test or Fisher's exact test was used for categorical variables. Receiver operating characteristic (ROC) curves were used to investigate the time from CPR to ECMO, lactate, and initial $\mathrm{pH}$ to identify survivors at discharge. The Youden index was used to determine the optimal cut-off values. Survival analysis was evaluated using the Kaplan-Meier method and log rank test to assess the effect of risk level on the likelihood of death at 6 months after VA ECMO initiation in patients.

Variables that achieved statistical significance $(p<$ $0.05)$ in univariate analysis were subsequently subjected to multivariate analysis using logistic regression analysis. To derive survival component scores, each predictor's coefficient retained in the multiple logistic regression model was divided by the model's smallest coefficient, multiplied by 5 , and rounded to the nearest integer. The predictive accuracy of this scaled score was quantified with area under the ROC curve (AUC) estimates. Goodness of fit was verified by the Hosmer-Lemeshow test. Internal validation of the risk score was performed using 1000 bootstrap resamples. All statistical analyses were performed using IBM SPSS Statistics for Windows, Version 22.0 (IBM Corp., Armonk, NY) and SAS (version 9.4; SAS Institute, Cary, NC).

\section{Results}

Patient characteristics and outcome of refractory cardiac arrest with E-CPR

In total, 359 patients received ECMO therapy at our hospital during the study period, of whom 112 patients 
who met the inclusion criteria were enrolled in the study (Fig. 1). The majority of the patients were male (74.1\%; median age, 59.5 years). The causes of cardiac arrest were acute myocardial infarction (58.9\%), cardiomyopathy (11.6\%), myocarditis (10.7\%), pulmonary embolism $(8.0 \%)$, and others $(10.7 \%)$. Cardiac arrests were classified by location as IHCA (58.0\%), OHCA (24.1\%), or EDCA (17.9\%). Furthermore, 63 patients (56.2\%) presented with initial shockable rhythm, and the remaining patients presented with nonshockable rhythm, including asystole and PEA. The patients had a median low-flow time (CPR to ECMO time) of $46.0 \mathrm{~min}$ (IQR, 35.0-57.0 min). Overall, 45 patients (40.2\%) survived to discharge, and 41 patients $(36.6 \%)$ were alive during the 6 -month follow-up period. Furthermore, 34 patients $(30.4 \%)$ had good neurological outcome at discharge, and 29 patients (25.9\%) had good neurological outcome during the 6month follow-up period.

\section{Comparison of clinical outcome between survivors and nonsurvivors at discharge}

Table 1 shows the comparison between survivors and nonsurvivors at discharge. Compared with nonsurvivors, survivors had similar underlying disease, a trend toward younger age (55.0 years [IQR, 45.0-66.0] vs 61.0 years [IQR, 54.0-68.0], $p=0.102)$, a higher proportion of acute myocardial infarctions $(p=0.030)$, a higher proportion of initial shockable rhythms $(p=0.0002)$, and a different distribution of the location of cardiac arrest $(p=0.043)$. Survivors had a significantly shorter low-flow time (CPR to ECMO time) $(p=0.001)$. Compared with nonsurvivors, survivors had lower lactate $(p=0.004)$, higher initial $\mathrm{pH}(p=0.014)$, and similar troponin $(p=0.350)$ and creatinine levels $(p=0.426)$. Survival to discharge was higher for EDCA than for OHCA $(65.0 \%$ vs. $33.3 \%, p=$ $0.0333)$ or IHCA $(65.0 \%$ vs. $35.4 \%, p=0.0198)$ and did not differ between OHCA and IHCA (33.3\% vs. $35.4 \%$, $p=0.8516)$. The rate of good neurological outcome at discharge was higher for EDCA than for OHCA (60\% vs. $18.5 \%, p=0.0038)$ or IHCA ( $60 \%$ vs. $26.2 \%, p=0.0055$ ) and did not differ between OHCA and IHCA (18.5\% vs. $26.2 \%, p=0.4368)$.

\section{Risk score construction and risk stratification of patient outcome after E-CPR}

In the univariate logistic regression analysis, the following variables significantly affected survival to discharge: age, location of cardiac arrest, CPR to ECMO, initial cardiac rhythm, serum lactate concentration, initial $\mathrm{pH}$, and cardiac arrest etiology. To stratify patient outcome before E-CPR use, we extracted clinically important factors before E-CPR use (Table 2) according to univariate and multivariate analyses. Laboratory data (serum lactate concentration and initial $\mathrm{pH}$ ) and cardiac arrest etiology are often unknown prior to ECMO and were not included in the multivariate analysis. Patient age lost its significance in the multivariate analysis. Three factors (cardiac arrest location, CPR to ECMO time, and initial cardiac rhythm) were identified as significant, with survival component scores of 5,7 , and 7 points, respectively. The survival risk of each patient was divided into three mortality risk levels: score $=0$, defined as high; score 5-12, defined as medium; and score 14-19, defined as low. Then, we compared the clinical outcome between the three risk groups. In total, 27 patients (24.1\%) were classified as high risk, 38 patients (33.9\%) as low risk, and the remaining patients as medium risk (Table 3). There were significant differences in clinical outcome between these three groups. Patients in the low-risk group had the best clinical outcome, with a survival to discharge rate of $65.8 \%$ and a survival to 6 months after discharge rate of $60.5 \%$. The rate of good neurological outcome in the low-risk group was $50 \%$ at discharge and $44.7 \%$ at 6 months after discharge (Fig. 2). The high-risk group had the worst clinical outcome, with none of the patients surviving at discharge (Fig. 3).

\section{Discussion}

In this study, we report that patients with refractory cardiac arrest had an overall survival rate of 40.2 , and $30.4 \%$ of patients were discharged with good neurological function after E-CPR use. These findings are consistent with those of previous studies of E-CPR for prolonged cardiac arrest [21-23, 25]. We attempted to stratify our patients into three clinical risk groups according to three clinical parameters (cardiac arrest location, low-flow time, and initial cardiac rhythm) before initiating E-CPR. A high rate $(65.8 \%)$ and a low rate $(0 \%)$ of survival to discharge can be discriminated with this clinical classification system. This is the first attempt to use pre-ECMO parameters to predict patient outcome in cases of refractory cardiac arrest. This finding may aid in shared decisionmaking regarding ECMO use when prolonged cardiac massage occurs in daily practice.

The prognosis for patients with prolonged cardiac arrest is ominous when they are refractory to C-CPR [26], with survival rates of less than $1 \%$. E-CPR has the ability to restore blood flow to prevent metabolic dysfunction in the highly lethal situation of prolonged cardiac arrest $[26,27]$. Previous investigations have shown that E-CPR can improve the clinical outcome in patients with IHCA beyond $10 \mathrm{~min}[19,28,29]$. Observational studies have also found that early E-CPR use may help to improve the neurological outcome in patients with prolonged cardiac arrest $[3,5,24,30]$. Early studies found a more favorable outcome of E-CPR among IHCA patients than among OHCA patients [7, 22, 25] because of a shorter interval from cardiac arrest to active ECMO support 
Table 1 Demographic characteristics of patients after refractory cardiac arrest

\begin{tabular}{|c|c|c|c|c|c|}
\hline \multirow{3}{*}{ Variable } & & \multirow[b]{2}{*}{$\begin{array}{l}\text { Total } \\
N=112(100 \%)\end{array}$} & \multicolumn{2}{|c|}{ Survival to discharge } & \multirow{3}{*}{$P$-value } \\
\hline & & & \multirow{2}{*}{$\begin{array}{l}\text { No } \\
N=67(59.8 \%) \\
N(\%)\end{array}$} & \multirow{2}{*}{$\begin{array}{l}\text { Yes } \\
N=45(40.2 \%) \\
N(\%)\end{array}$} & \\
\hline & & N (\%) & & & \\
\hline Gender & Male & $83(74.1)$ & $52(77.6)$ & $31(68.9)$ & 0.302 \\
\hline \multirow[t]{2}{*}{ Age } & Median (IQR) ${ }^{a}$ & $59.5(50.0-67.5)$ & $61.0(54.0-68.0)$ & $55.0(45.0-66.0)$ & 0.102 \\
\hline & $\geq 55$ & $72(64.3)$ & 49(73.1) & 23(51.1) & 0.017 \\
\hline \multirow[t]{5}{*}{ Etiology of cardiac arrest } & Acute myocardial infarction & $66(58.9)$ & $38(56.7)$ & $28(62.2)$ & 0.030 \\
\hline & Cardiomyopathy & $13(11.6)$ & $9(13.4)$ & $4(8.9)$ & \\
\hline & Myocarditis & $12(10.7)$ & $3(4.5)$ & $9(20.0)$ & \\
\hline & Pulmonary embolism & $9(8.0)$ & $8(11.9)$ & $1(2.2)$ & \\
\hline & Others & $12(10.7)$ & $9(13.4)$ & $3(6.7)$ & \\
\hline \multirow[t]{7}{*}{ Underlying disease } & Coronary artery disease & $100(89.3)$ & $59(88.1)$ & $41(91.1)$ & 0.759 \\
\hline & Hypertension & $62(55.4)$ & $39(58.2)$ & $23(51.1)$ & 0.459 \\
\hline & Diabetes mellitus & $53(47.3)$ & $32(47.8)$ & $21(46.7)$ & 0.909 \\
\hline & Pulmonary disease & $28(25.0)$ & $17(25.4)$ & $11(24.4)$ & 0.911 \\
\hline & Renal insufficiency & $36(32.1)$ & $23(34.3)$ & $13(28.9)$ & 0.546 \\
\hline & Chronic liver disease & $12(10.7)$ & $6(9.0)$ & $6(13.3)$ & 0.539 \\
\hline & Hyperlipidemia & $26(23.2)$ & $16(23.9)$ & $10(22.2)$ & 0.839 \\
\hline \multirow[t]{3}{*}{ Location of cardiac arrest } & $\mathrm{OHCA}^{b}$ & $27(24.1)$ & $18(26.9)$ & $9(20.0)$ & 0.043 \\
\hline & $\mathrm{EDCA}^{\mathrm{C}}$ & $20(17.9)$ & $7(10.4)$ & $13(28.9)$ & \\
\hline & $\mathrm{HCA}^{d}$ & 65 (58.0) & $42(62.7)$ & $23(51.1)$ & \\
\hline \multirow[t]{2}{*}{ Initial cardiac rhythm } & Asystole/PEA & $49(43.8)$ & $39(58.2)$ & $10(22.2)$ & 0.002 \\
\hline & Pulseless $\mathrm{VT}^{e /} \mathrm{Vf}^{f}$ & $63(56.2)$ & $28(41.8)$ & $35(77.8)$ & \\
\hline \multirow[t]{2}{*}{ CPR to ECMO (min) } & Median (IQR) & $46.0(35.0-57.0)$ & $50.0(42.0-60.0)$ & $38.0(35.0-46.0)$ & 0.001 \\
\hline & $\geq 48$ & $53(47.3)$ & $43(64.2)$ & $10(22.2)$ & $<0.001$ \\
\hline Lactate (IU/ml) & Median (IQR) & $8.6(5.7-13.1)$ & $9.8(6.6-15.3)$ & $7.0(5.2-9.5)$ & 0.004 \\
\hline Troponin (ng/L) & Median (IQR) & $3.2(0.7-24.4)$ & $3.6(0.7-37.2)$ & $2.5(0.5-11.0)$ & 0.350 \\
\hline Initial pH & Median (IQR) & $7.3(7.1-7.3)$ & $7.2(7.1-7.3)$ & $7.3(7.2-7.4)$ & 0.014 \\
\hline Creatinine (mg/dL) & Median (IQR) & $1.6(1.2-2.0)$ & $1.7(1.3-2.0)$ & $1.4(1.1-1.9)$ & 0.426 \\
\hline $\mathrm{PCl}$ & Yes & $75(67.0)$ & $47(70.1)$ & $28(62.2)$ & 0.382 \\
\hline IABP & Yes & $60(53.6)$ & $39(58.2)$ & $21(46.7)$ & 0.230 \\
\hline Dialysis & Yes & $34(30.4)$ & $19(28.4)$ & $15(33.3)$ & 0.575 \\
\hline Therapeutic Hypothermia & Yes & $52(46.4)$ & $31(46.3)$ & $21(46.7)$ & 0.967 \\
\hline ROSC & Yes & $108(96.4)$ & $63(94.0)$ & $45(100.0)$ & 0.147 \\
\hline ECMO duration (hour) & Median (IQR) & $71.0(26-124)$ & $44.5(19-101)$ & $93.0(66-148)$ & $<0.001$ \\
\hline Hospital stay (day) & Median (IQR) & $14.0(3.5-27.0)$ & $5.0(2.0-16.0)$ & $24.0(16.0-47.0)$ & $<0.001$ \\
\hline Follow-up time (month) & Median (IQR) & $0.6(0.1-25.5)$ & $0.1(0.0-0.5)$ & $33.8(15.0-48.6)$ & $<0.001$ \\
\hline \multirow[t]{5}{*}{ Neurologic function at discharge (CPC score) } & 1 & $32(28.6)$ & $0(0.0)$ & $32(71.1)$ & $<0.001$ \\
\hline & 2 & $2(1.8)$ & $0(0.0)$ & $2(4.4)$ & \\
\hline & 3 & $5(4.5)$ & $0(0.0)$ & $5(11.1)$ & \\
\hline & 4 & $6(5.4)$ & $0(0.0)$ & $6(13.3)$ & \\
\hline & 5 & $67(59.8)$ & $0(0.0)$ & $0(0.0)$ & \\
\hline Good neurologic function at discharge & Yes $(C P C \leq 2)^{g}$ & $34(30.4)$ & $0(0.0)$ & $34(75.6)$ & $<0.001$ \\
\hline Survival-6 months later & Yes & $41(36.6)$ & $0(0.0)$ & $41(91.1)$ & \\
\hline Neurologic function-6 month later (CPC score) & 1 & $29(25.9)$ & $0(0.0)$ & $29(64.4)$ & $<0.001$ \\
\hline
\end{tabular}


Table 1 Demographic characteristics of patients after refractory cardiac arrest (Continued)

\begin{tabular}{|c|c|c|c|c|c|}
\hline \multirow[b]{3}{*}{ Variable } & & \multirow[b]{2}{*}{$\begin{array}{l}\text { Total } \\
N=112(100 \%)\end{array}$} & \multicolumn{2}{|c|}{ Survival to discharge } & \multirow{3}{*}{$P$-value } \\
\hline & & & $\begin{array}{l}\text { No } \\
N=67(59.8 \%)\end{array}$ & $\begin{array}{l}\text { Yes } \\
N=45 \text { (40.2\%) }\end{array}$ & \\
\hline & & $\mathrm{N}(\%)$ & N (\%) & N (\%) & \\
\hline & 2 & $0(0.0)$ & $0(0.0)$ & $0(0.0)$ & \\
\hline & 3 & $6(5.4)$ & $0(0.0)$ & $6(13.3)$ & \\
\hline & 4 & $6(5.4)$ & $0(0.0)$ & $6(13.3)$ & \\
\hline & 5 & 4 (3.6) & $0(0.0)$ & $4(8.9)$ & \\
\hline Good neurologic function- 6 months later & Yes $(C P C \leq 2)$ & $29(25.9)$ & $0(0.0)$ & $29(64.4)$ & \\
\hline
\end{tabular}

${ }^{\mathrm{a}} I Q R$ interquartile range

${ }^{\mathrm{b}} \mathrm{OCHA}$ out-of-hospital cardiac arrest

${ }^{\mathrm{E}} E D C A$ emergency department cardiac arrest

${ }^{\mathrm{d}} / \mathrm{HCA}$ in-hospital cardiac arrest

${ }^{\mathrm{e}} V T$ ventricular tachycardiaf

${ }^{f} V f$ ventricular fibrillation

${ }^{9} C P C$ cerebral performance category

among IHCA patients. A subsequent study showed that the clinical outcome of E-CPR can be similar between IHCA and OHCA patients with appropriate patient selection [31]. One strength of the present study is that we identified a unique type of cardiac arrest, EDCA. In this series with appropriate patient selection, we found no differences in clinical outcome between the IHCA and OHCA groups. Although E-CPR use in emergency departments was limited in a recent survey in the United States [32], we found that the EDCA group had better clinical outcome than the IHCA and OHCA groups. When patients present to the emergency department with subsequent development of cardiac arrest, these patients are more likely to receive prompt and high-quality CPR than other patients [33]. Even with prolonged cardiac arrest, these patients are most likely to have good prognostic factors and deserve aggressive E-CPR initiation in such a situation [3, 4].

The time interval from CPR initiation to ECMO is correlated with patient outcome. Previous studies showed that low-flow time (from CPR to ECMO) was strongly correlated with survival rate and neurological outcome [34, 35]. In the present study, the low-flow time was longer in nonsurvivors than in survivors (50 vs. $38 \mathrm{~min}, p<0.001$ ). Thus, earlier identification of patients with refractory cardiac arrest who are suited for E-CPR treatment may shorten the low-flow time to improve patient outcome [29, 36, 37].

Patient age is an important consideration when initiating E-CPR, taking into account the cost and benefit. Age is an important, but not the only, factor predicting survival after E-CPR for prolonged cardiac arrest [17]. In our study, compared with nonsurvivors, survivors had a higher proportion in the younger age group ( $<55$ years) $(p=0.018)$. In some studies, E-CPR use was excluded for patients over 60 years of age $[4,32]$. We suggest that such younger-old patients should not be excluded from E-CPR use [38]. We consider 75 years of age an exclusion criterion for E-CPR use in our institution, similar to most other authors [17, 32, 38, 39], because of the low rate of benefits from E-CPR in such old-old patients.

Another important finding of our study is that nonshockable cardiac rhythm should not be the sole contraindication to E-CPR use for prolonged cardiac arrest. Many E-CPR programs exclude patients with nonshockable rhythms due to very limited outcomes after C-CPR $[4,40]$. We found that compared with shockable cardiac arrest, nonshockable cardiac arrest had a worse prognosis. However, 10 of 49 patients (20.4\%) presenting with nonshockable rhythms survived to discharge with E-CPR use. Our observations, along with those of other recent reports $[3,41,42]$, suggest that we need to consider clinical parameters other than rhythm alone as contraindications to E-CPR use.

The current study is novel because it builds the TLR score (low-flow Time, cardiac arrest Location, and initial cardiac arrest Rhythm) with three preECMO factors to stratify our patient outcome after receiving E-CPR with internal validation by bootstrap simulations. As previously mentioned, patient outcome with E-CPR is affected by a complex interplay of multiple factors [17, 21-23, 43]. Reported predictors of survival and neurological function include age, initial cardiac rhythm, low-flow time, arterial $\mathrm{pH}$ value, and serum lactate level [16, 21, 43]. These variable clinical predictors reveal not only the underlying patient characteristics but also the quality of the resuscitation process. For example, initial serum lactate is an indicator of tissue hypoxia [26, 44], but dynamic changes in lactate level also reflect the effect of ECMO therapy [16, 45]. In our study, EDCA was one factor in patient outcome, and such clinical parameters to predict patient outcome are important during E-CPR. 
Table 2 Logistic regression analysis of survival to discharge

\begin{tabular}{|c|c|c|c|c|c|c|c|}
\hline \multirow[b]{2}{*}{ Predictor } & \multicolumn{3}{|c|}{ Univariate analysis (crude) } & \multicolumn{4}{|c|}{ Multivariate analysis (adjusted) } \\
\hline & Coefficient & $\mathrm{OR}(95 \% \mathrm{Cl})$ & $P$-value & Coefficient & $\mathrm{OR}(95 \% \mathrm{Cl})$ & $P$-value & Score \\
\hline \multicolumn{8}{|l|}{ Age } \\
\hline$<55$ & 0.957 & $2.604(1.175-5.771)$ & 0.018 & & & & \\
\hline$>=55$ & & 1.000 & & & & & \\
\hline \multicolumn{8}{|l|}{ Location of cardiac arrest } \\
\hline $\mathrm{OHCA}^{\mathrm{a}}$ or $\mathrm{IHCA}^{b}$ & & 1.000 & & & 1.000 & & \\
\hline Emergency department & 1.248 & $3.482(1.263-9.600)$ & 0.016 & 1.312 & $3.715(1.190-11.596)$ & 0.024 & 5 \\
\hline \multicolumn{8}{|l|}{$\mathrm{CPR}^{c}$ to $\mathrm{ECMO}^{d}$ (min) } \\
\hline$<48$ & 1.836 & $6.271(2.648-14.851)$ & $<0.001$ & 1.743 & $5.714(2.221-14.698)$ & $<0.001$ & 7 \\
\hline$>=48$ & & 1.000 & & & 1.000 & & \\
\hline \multicolumn{8}{|l|}{ Initial cardiac rhythm } \\
\hline Asystole or PEA & & 1.000 & & & 1.000 & & \\
\hline Pulseless $\mathrm{VT}^{f}$ or $\mathrm{V}^{g}$ & 1.584 & $4.875(2.075-11.453)$ & $<0.001$ & 1.712 & $5.543(2.057-14.937)$ & 0.001 & 7 \\
\hline \multicolumn{8}{|l|}{ Lactate (IU/ml) } \\
\hline$<=9.7$ & 1.269 & $3.556(1.451-8.711)$ & 0.006 & & & & \\
\hline$>9.7$ & & 1.000 & & & & & \\
\hline \multicolumn{8}{|l|}{ Initial pH } \\
\hline$<7.31$ & & 1.000 & & & & & \\
\hline$>=7.31$ & 1.171 & $3.225(1.394-7.464)$ & 0.006 & & & & \\
\hline \multicolumn{8}{|l|}{ Eitology of cardiac arrest } \\
\hline Acute myocardial infarction & & 1.000 & & & & & \\
\hline Cardiomyopathy & -0.506 & $0.603(0.169-2.158$ & 0.437 & & & & \\
\hline Myocarditis & 1.404 & $4.071(1.009-16.426)$ & 0.049 & & & & \\
\hline Pulmonary embolism & -1.774 & $0.170(0.020-1.435)$ & 0.103 & & & & \\
\hline Others & -0.793 & $0.452(0.112-1.825)$ & 0.265 & & & & \\
\hline
\end{tabular}

Hosmer-Lemeshow goodness-of-fit test indicated no evidence of lack of fit in the selected model $(p=0.185) . \mathrm{OR}=$ Odds ratio

${ }^{a}$ OHCA Out-of-hospital cardiac arrest, ${ }^{b}$ IHCA In-hospital cardiac arrest, ${ }^{c}$ CPR Cardiopulmonary resuscitation, ${ }^{d}$ ECMO Extracorporeal membrane oxygenation, ${ }^{e}$ PEA Pulselss electrical activity, ${ }^{f}$ VT Ventricular tachycardia, ${ }^{g}$ Vf Ventricular fibrillation

We identified a high-risk group of patients, i.e., those who had no favorable prognostic factors and thus a very low chance $(0 \%)$ of benefit from E-CPR. Low-risk patients, i.e., those with $>14$ points in our scoring system, were most likely to benefit from ECPR following refractory cardiac arrest, with a $65.8 \%$ survival rate at discharge. E-CPR has the potential to put patients who are at the end of their natural life through a very invasive intervention with no meaningful likelihood of benefit. In addition, the cost of E-CPR is substantial [8], and we believe that such a risk stratification is helpful to the physician for identifying appropriate patients for E-CPR. However, a larger study involving more patients with external validation of our observations is required.

Our study has several limitations. First, the study was retrospective, and the number of cases was limited. Second, the quality of CPR performed by personnel in the

Table 3 Clinical outcome according to risk stratification of patients

\begin{tabular}{|c|c|c|c|c|c|c|c|c|c|}
\hline \multirow[t]{2}{*}{ Risk Group } & \multirow[b]{2}{*}{ Total } & \multicolumn{2}{|c|}{ Survival to discharge } & \multicolumn{2}{|c|}{ Survival 6 months after discharge } & \multicolumn{2}{|c|}{ Good function at discharge } & \multicolumn{2}{|c|}{$\begin{array}{l}\text { Good function } 6 \text { months } \\
\text { after discharge }\end{array}$} \\
\hline & & $\mathrm{N}$ & $\%$ & N & $\%$ & N & $\%$ & N & $\%$ \\
\hline & 112 & 45 & 40.2 & 41 & 36.6 & 34 & 30.4 & 29 & 25.9 \\
\hline $\operatorname{High}(S=0)$ & 27 & 0 & 0.0 & 0 & 0.0 & 0 & 0.0 & 0 & 0.0 \\
\hline Medium (S = 5-12) & 47 & 20 & 42.6 & 18 & 38.3 & 15 & 31.9 & 12 & 25.5 \\
\hline Low $(S=14-19)$ & 38 & 25 & 65.8 & 23 & 60.5 & 19 & 50.0 & 17 & 44.7 \\
\hline
\end{tabular}




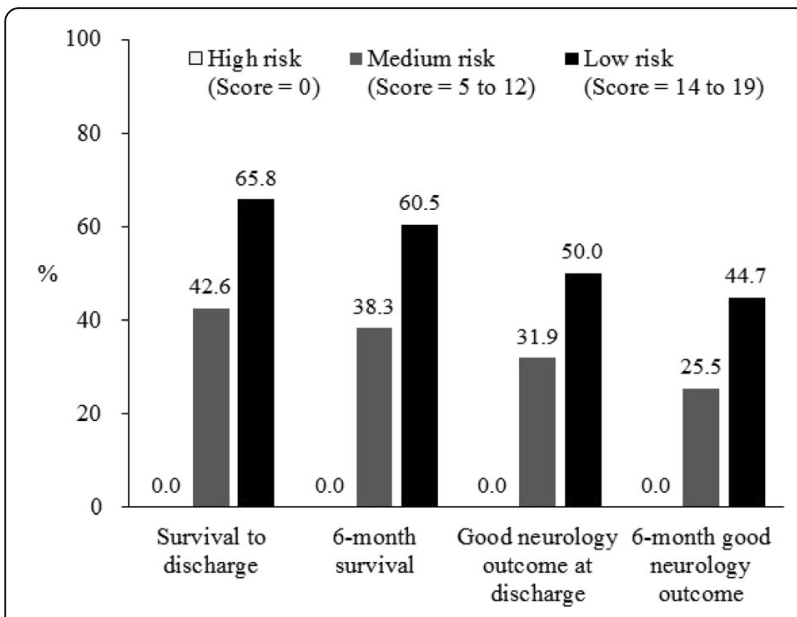

Fig. 2 Clinical outcome according to risk group

prehospital setting, the in-hospital setting, and at the emergency department differed and was difficult to evaluate, and it may have been an important cofounding factor influencing patient outcome. Finally, the proposed risk stratification system is used to stratify patient outcome only in our institution, which is equipped to perform E-CPR even in the emergency department. Future prospective studies with larger sample sizes are required to verify these findings and extrapolate them to the wider population.

\section{Conclusions}

This study has created a risk stratification system for predicting survival of E-CPR for refractory cardiac arrest. The score identifies a low-risk group of patients with a high rate of survival to discharge (65.8\%) and good neurological function at discharge $(60.5 \%)$ and a high-

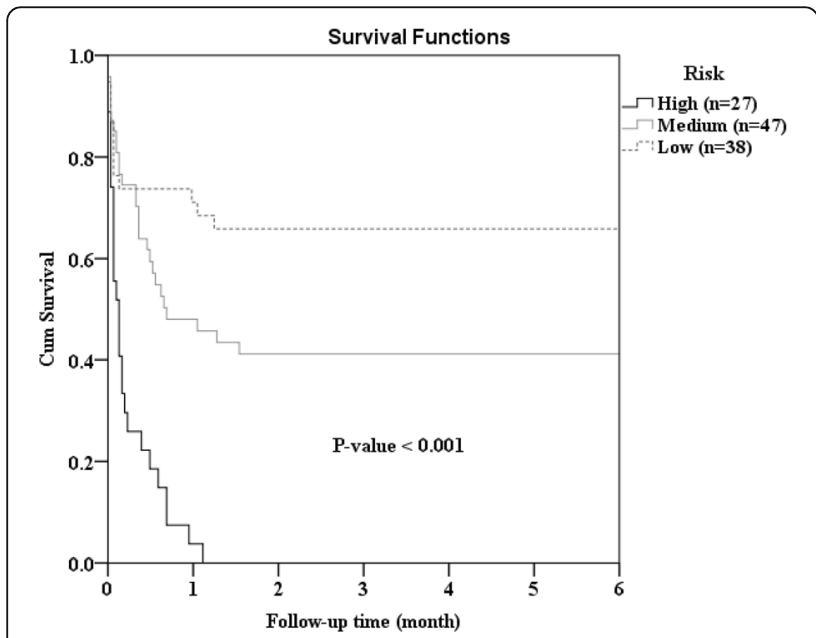

Fig. 3 Survival analysis according to risk group. Kaplan-Meier survival curves for extracorporeal cardiopulmonary resuscitation in high-risk, medium-risk, and low-risk groups $(p<0.0001)$ risk group with a zero rate of survival to discharge. Such risk stratification with pre-E-CPR parameters to predict patient survival after E-CPR may help clinical decisionmaking for E-CPR implementation.

\section{Abbreviations}

C-CPR: Conventional cardiopulmonary resuscitation; CPC: Cerebral performance category; CPR: Cardiopulmonary resuscitation; ECPR: Extracorporeal cardiopulmonary resuscitation; ECMO: Extracorporeal membrane oxygenation; EDCA: Emergency department cardiac arrest; IHCA: In-hospital cardiac arrest; OHCA: Out-of-hospital cardiac arrest; ROSC: Return of spontaneous circulation; SAVE: Survival After Veno-arterial ECMO

\section{Acknowledgments}

The authors would like to thank Enago (www.enago.tw) and Nature Research Editing Service (www.authorservices.springernature.com) for the English language review.

\section{Authors' contributions}

Fu-Yuan Siao and Chun-Wen Chiu Contributed equally to this manuscript. Fu-Yuan Siao and Hsu-Heng Yen conceived and designed the study. All authors contributed substantially to the revision of the manuscript. All authors read and approved the final manuscript.

\section{Funding}

The authors received research funding from Changhua Christian Hospital (105-CCH-IRP-071 and 108-CCH-IRP-018).

\section{Ethics approval and consent to participate}

The study was approved by the Institutional Review Board of Changhua Christian Hospital (IRB No 141103).

\section{Consent for publication}

Not applicable.

\section{Competing interests}

The authors declare that they have no competing interests.

\section{Author details}

'Department of Emergency Medicine, Changhua Christian Hospital, Changhua, Taiwan. ${ }^{2}$ Department of Critical Care Medicine, Changhua Christian Hospital, Changhua, Taiwan. ${ }^{3}$ Department of Mechanical Engineering, Chung Yuan Christian University, Taoyuan, Taiwan. ${ }^{4}$ Epidemiology and Biostatistics Center, Changhua Christian Hospital, Changhua, Taiwan. ${ }^{5}$ Department of Cardiovascular Surgery, Changhua Christian Hospital, Changhua, Taiwan. ${ }^{6}$ Department of Internal Medicine, Changhua Christian Hospital, Changhua, Taiwan. ${ }^{7}$ College of Medicine, Chung-Shan Medical University, Taichung, Taiwan.

Received: 24 August 2019 Accepted: 8 June 2020

Published online: 23 June 2020

\section{References}

1. Chiu CW, Yen HH, Chiu CC, Chen YC, Siao FY. Prolonged cardiac arrest: successful resuscitation with extracorporeal membrane oxygenation. Am J Emerg Med. 2013;31(11):1627 e1625-6.

2. Chiu CC, Yen HH, Chen YL, Siao FY. Severe hyperkalemia with refractory ventricular fibrillation: successful resuscitation using extracorporeal membrane oxygenation. Am J Emerg Med. 2014;32(8):943 e945-6.

3. Siao FY, Chiu CC, Chiu CW, Chen YC, Chen YL, Hsieh YK, Lee CH, Wu CT, Chou CC, Yen HH. Managing cardiac arrest with refractory ventricular fibrillation in the emergency department: conventional cardiopulmonary resuscitation versus extracorporeal cardiopulmonary resuscitation. Resuscitation. 2015;92:70-6.

4. Tonna JE, Selzman CH, Mallin MP, Smith BR, Youngquist ST, Koliopoulou A, Welt F, Stoddard KD, Nirula R, Barton R, et al. Development and implementation of a comprehensive, multidisciplinary emergency department extracorporeal membrane oxygenation program. Ann Emerg Med. 2017;70(1):32-40. 
5. Patricio D, Peluso L, Brasseur A, Lheureux O, Belliato M, Vincent JL, Creteur J, Taccone FS. Comparison of extracorporeal and conventional cardiopulmonary resuscitation: a retrospective propensity score matched study. Crit Care. 2019;23(1):27.

6. Conseil francais de reanimation $c$, Societe francaise d'anesthesie et de $r$, Societe francaise de c, Societe francaise de chirurgie thoracique et $c_{\text {, }}$ Societe francaise de medecine du, Societe francaise de $p$, Groupe francophone de reanimation et d'urgence $p$, Societe francaise de $p$, Societe de reanimation de langue $f$. Guidelines for indications for the use of extracorporeal life support in refractory cardiac arrest. French Ministry of Health. Ann Fr Anesth Reanim. 2009;28(2):182-90.

7. Johnson NJ, Acker M, Hsu CH, Desai N, Vallabhajosyula P, Lazar S, Horak J, Wald J, McCarthy F, Rame E, et al. Extracorporeal life support as rescue strategy for out-of-hospital and emergency department cardiac arrest. Resuscitation. 2014;85(11):1527-32.

8. Karagiannidis C, Brodie D, Strassmann S, Stoelben E, Philipp A, Bein T, Muller $T$, Windisch W. Extracorporeal membrane oxygenation: evolving epidemiology and mortality. Intensive Care Med. 2016;42(5):889-96.

9. Pozzi M, Koffel C, Armoiry X, Pavlakovic I, Neidecker J, Prieur C, Bonnefoy E, Robin J, Obadia JF. Extracorporeal life support for refractory out-of-hospital cardiac arrest: should we still fight for? A single-Centre, 5-year experience. Int J Cardiol. 2016;204:70-6.

10. Stub D, Bernard S, Pellegrino V, Smith K, Walker T, Sheldrake J, Hockings L, Shaw J, Duffy SJ, Burrell A, et al. Refractory cardiac arrest treated with mechanical CPR, hypothermia, ECMO and early reperfusion (the CHEER trial). Resuscitation. 2015;86:88-94.

11. Thiagarajan RR, Barbaro RP, Rycus PT, McMullan DM, Conrad SA, Fortenberry $J \mathrm{D}$, Paden ML, centers Em. Extracorporeal life support organization registry international report 2016. ASAIO J. 2017:63(1):60-7.

12. Brooks SC, Anderson ML, Bruder E, Daya MR, Gaffney A, Otto CW, Singer AJ, Thiagarajan RR, Travers AH. Part 6: alternative techniques and ancillary devices for cardiopulmonary resuscitation: 2015 American Heart Association guidelines update for cardiopulmonary resuscitation and emergency cardiovascular care. Circulation. 2015:132(18 Suppl 2):S436-43.

13. Henry B, Verbeek PR, Cheskes S. Extracorporeal cardiopulmonary resuscitation in out-of-hospital cardiac arrest: ethical considerations. Resuscitation. 2019;137:1-6

14. Bol ME, Suverein MM, Lorusso R, Delnoij TSR, Brandon Bravo Bruinsma GJ, Otterspoor L, Kuijpers M, Lam KY, APJ V, Elzo Kraemer CV, et al. Early initiation of extracorporeal life support in refractory out-of-hospital cardiac arrest: design and rationale of the INCEPTION trial. Am Heart J. 2018;210:5868.

15. Grunau B, Hornby L, Singal RK, Christenson J, Ortega-Deballon I, Shemie SD, Bashir J, Brooks SC, Callaway CW, Guadagno E, et al. Extracorporeal cardiopulmonary resuscitation for refractory out-of-hospital cardiac arrest: the state of the evidence and framework for application. Can J Cardiol. 2018;34(2):146-55.

16. Rigamonti F, Montecucco F, Boroli F, Rey F, Gencer B, Cikirikcioglu M, Reverdin S, Carbone F, Noble S, Roffi M, et al. The peak of blood lactate during the first $24 \mathrm{~h}$ predicts mortality in acute coronary syndrome patients under extracorporeal membrane oxygenation. Int J Cardiol. 2016;221:741-5.

17. Yu HY, Wang CH, Chi NH, Huang SC, Chou HW, Chou NK, Chen YS. Effect of interplay between age and low-flow duration on neurologic outcomes of extracorporeal cardiopulmonary resuscitation. Intensive Care Med. 2019; 45(1):44-54

18. Chen WC, Huang KY, Yao CW, Wu CF, Liang SJ, Li CH, Tu CY, Chen HJ. The modified SAVE score: predicting survival using urgent veno-arterial extracorporeal membrane oxygenation within 24 hours of arrival at the emergency department. Crit Care. 2016;20(1):336.

19. Schmidt M, Burrell A, Roberts L, Bailey M, Sheldrake J, Rycus PT, Hodgson C, Scheinkestel C, Cooper DJ, Thiagarajan RR, et al. Predicting survival after ECMO for refractory cardiogenic shock: the survival after veno-arterial-ECMO (SAVE)-score. Eur Heart J. 2015;36(33):2246-56.

20. Muller G, Flecher E, Lebreton G, Luyt CE, Trouillet JL, Brechot N, Schmidt M, Mastroianni C, Chastre J, Leprince P, et al. The ENCOURAGE mortality risk score and analysis of long-term outcomes after VA-ECMO for acute myocardial infarction with cardiogenic shock. Intensive Care Med. 2016; 42(3):370-8.

21. Debaty G, Babaz V, Durand M, Gaide-Chevronnay L, Fournel E, Blancher M, Bouvaist $H$, Chavanon O, Maignan M, Bouzat $P$, et al. Prognostic factors for extracorporeal cardiopulmonary resuscitation recipients following out-of- hospital refractory cardiac arrest. A systematic review and meta-analysis. Resuscitation. 2017;112:1-10.

22. Zhang Q, Qi Z, Liu B, Li C. Predictors of survival and favorable neurological outcome in patients treated with targeted temperature management after cardiac arrest: a systematic review and meta-analysis. Heart Lung. 2018;47(6): 602-9.

23. Beyea MM, Tillmann BW, lansavichene AE, Randhawa VK, Van Aarsen K, Nagpal AD. Neurologic outcomes after extracorporeal membrane oxygenation assisted CPR for resuscitation of out-of-hospital cardiac arrest patients: a systematic review. Resuscitation. 2018;130:146-58.

24. Huang HW, Chiu CC, Yen HH, Chen YL, Siao FY. Prolonged pulseless electrical activity: successful resuscitation using extracorporeal membrane oxygenation. Am J Emerg Med. 2015;33(3):474 e475-6.

25. Bednarczyk JM, White CW, Ducas RA, Golian M, Nepomuceno R, Hiebert B, Bueddefeld D, Manji RA, Singal RK, Hussain F, et al. Resuscitative extracorporeal membrane oxygenation for in hospital cardiac arrest: a Canadian observational experience. Resuscitation. 2014:85(12):1713-9.

26. Patil KD, Halperin HR, Becker LB. Cardiac arrest: resuscitation and reperfusion. Circ Res. 2015;116(12):2041-9.

27. Trummer G, Foerster K, Buckberg GD, Benk C, Heilmann C, Mader I, Feuerhake F, Liakopoulos O, Brehm K, Beyersdorf F. Successful resuscitation after prolonged periods of cardiac arrest: a new field in cardiac surgery. J Thorac Cardiovasc Surg. 2010;139(5):1325-32 1332 e1321-1322.

28. Chen YS, Lin JW, Yu HY, Ko WJ, Jerng JS, Chang WT, Chen WJ, Huang SC, Chi NH, Wang $\mathrm{CH}$, et al. Cardiopulmonary resuscitation with assisted extracorporeal life-support versus conventional cardiopulmonary resuscitation in adults with in-hospital cardiac arrest: an observational study and propensity analysis. Lancet. 2008;372(9638):554-61.

29. Chan PS, Spertus JA, Krumholz HM, Berg RA, Li Y, Sasson C, Nallamothu BK. Get with the guidelines-resuscitation registry I: a validated prediction tool for initial survivors of in-hospital cardiac arrest. Arch Intern Med. 2012; 172(12):947-53.

30. Komeyama S, Takagi K, Tsuboi H, Tsuboi S, Morita Y, Yoshida R, Kanzaki Y, Nagai $H$, Ikai $Y$, Furui $K$, et al. The early initiation of extracorporeal life support may improve the neurological outcome in adults with cardiac arrest due to cardiac events. Intern Med. 2019;58(10):1391-7.

31. Wang CH, Chou NK, Becker LB, Lin JW, Yu HY, Chi NH, Hunag SC, Ko WJ, Wang SS, Tseng LJ, et al. Improved outcome of extracorporeal cardiopulmonary resuscitation for out-of-hospital cardiac arrest--a comparison with that for extracorporeal rescue for in-hospital cardiac arrest. Resuscitation. 2014;85(9):1219-24.

32. Tonna JE, Johnson NJ, Greenwood J, Gaieski DF, Shinar Z, Bellezo JM, Becker L, Shah AP, Youngquist ST, Mallin MP, et al. Practice characteristics of emergency department extracorporeal cardiopulmonary resuscitation (eCPR) programs in the United States: the current state of the art of emergency department extracorporeal membrane oxygenation (ED ECMO). Resuscitation. 2016;107:38-46.

33. Kayser RG, Ornato JP, Peberdy MA. American Heart Association National Registry of cardiopulmonary R: cardiac arrest in the emergency department: a report from the National Registry of cardiopulmonary resuscitation. Resuscitation. 2008;78(2):151-60.

34. Wengenmayer T, Rombach S, Ramshorn F, Biever P, Bode C, Duerschmied $D$, Staudacher DL. Influence of low-flow time on survival after extracorporeal cardiopulmonary resuscitation (eCPR). Crit Care. 2017;21(1): 157.

35. Otani T, Sawano H, Natsukawa T, Nakashima T, Oku H, Gon C, Takahagi M, Hayashi Y. Low-flow time is associated with a favorable neurological outcome in out-of-hospital cardiac arrest patients resuscitated with extracorporeal cardiopulmonary resuscitation. J Crit Care. 2018;48:15-20.

36. Ryu JA, Cho YH, Sung K, Choi SH, Yang JH, Choi JH, Lee DS, Yang JH. Predictors of neurological outcomes after successful extracorporeal cardiopulmonary resuscitation. BMC Anesthesiol. 2015;15:26.

37. Park BW, Seo DC, Moon IK, Chung JW, Bang DW, Hyon MS, Kim SK, Chang WH, Youm W. Pulse pressure as a prognostic marker in patients receiving extracorporeal life support. Resuscitation. 2013;84(10):1404-8.

38. Tseng LJ, Yu HY, Wang CH, Chi NH, Huang SC, Chou HW, Shih HC, Chou NK Chen YS. Impact of Age-Adjusted Charlson Comorbidity on Hospital Survival and Short-Term Outcome of Patients with Extracorporeal Cardiopulmonary Resuscitation. J Clin Med. 2018;7(10):313.

39. Lee W, Kim Y, Choi H, Kim H, Lee S, Lee H, Chee H, Kim J, Hwang J, Lee S, et al. Advanced age as a predictor of survival and weaning in Venoarterial 
extracorporeal oxygenation: a retrospective observational study. Biomed Res Int. 2017;2017:3505784.

40. Meaney PA, Nadkarni VM, Kern KB, Indik JH, Halperin HR, Berg RA. Rhythms and outcomes of adult in-hospital cardiac arrest. Crit Care Med. 2010;38(1): $101-8$.

41. Yannopoulos D, Bartos JA, Raveendran G, Conterato M, Frascone RJ, Trembley A, John R, Connett J, Benditt DG, Lurie KG, et al. Coronary artery disease in patients with out-of-hospital refractory ventricular fibrillation cardiac arrest. J Am Coll Cardiol. 2017;70(9):1109-17.

42. Pabst D, Brehm CE. Is pulseless electrical activity a reason to refuse cardiopulmonary resuscitation with ECMO support? Am J Emerg Med. 2018; 36(4):637-40.

43. D'Arrigo S, Cacciola S, Dennis M, Jung C, Kagawa E, Antonelli M, Sandroni C. Predictors of favourable outcome after in-hospital cardiac arrest treated with extracorporeal cardiopulmonary resuscitation: a systematic review and meta-analysis. Resuscitation. 2017;121:62-70.

44. Megarbane B, Deye N, Aout M, Malissin I, Resiere D, Haouache H, Brun P Haik W, Leprince P, Vicaut E, et al. Usefulness of routine laboratory parameters in the decision to treat refractory cardiac arrest with extracorporeal life support. Resuscitation. 2011;82(9):1154-61.

45. Slottosch I, Liakopoulos O, Kuhn E, Scherner M, Deppe AC, Sabashnikov A, Mader N, Choi YH, Wippermann J, Wahlers T. Lactate and lactate clearance as valuable tool to evaluate ECMO therapy in cardiogenic shock. J Crit Care. 2017;42:35-41.

\section{Publisher's Note}

Springer Nature remains neutral with regard to jurisdictional claims in published maps and institutional affiliations.

Ready to submit your research? Choose BMC and benefit from:

- fast, convenient online submission

- thorough peer review by experienced researchers in your field

- rapid publication on acceptance

- support for research data, including large and complex data types

- gold Open Access which fosters wider collaboration and increased citations

- maximum visibility for your research: over $100 \mathrm{M}$ website views per year

At BMC, research is always in progress.

Learn more biomedcentral.com/submissions 